\title{
Expert System for Sintering Process Control
}

\author{
Xiaohui Fan, Xuling Chen and Yi Wang \\ Central South University \\ China
}

\section{Introduction}

Sintering is a method that makes powdered materials (such as fine ore or preparation concentrate) into block mass under conditions involving incomplete fusion by heating to high temperature. Its production is sinter which is irregular and porous (FU et al., 1996).

The following parts are usually included in sintering process: acceptance and storage of iron-containing raw materials, fuel and flux; crushing and screening of raw materials, fuel and flux; batching, mix-granulation, feeding, ignition and sintering of mix material; crushing, screening, cooling and size-stabilization of sinter. The flowchart is shown in Fig. 1.

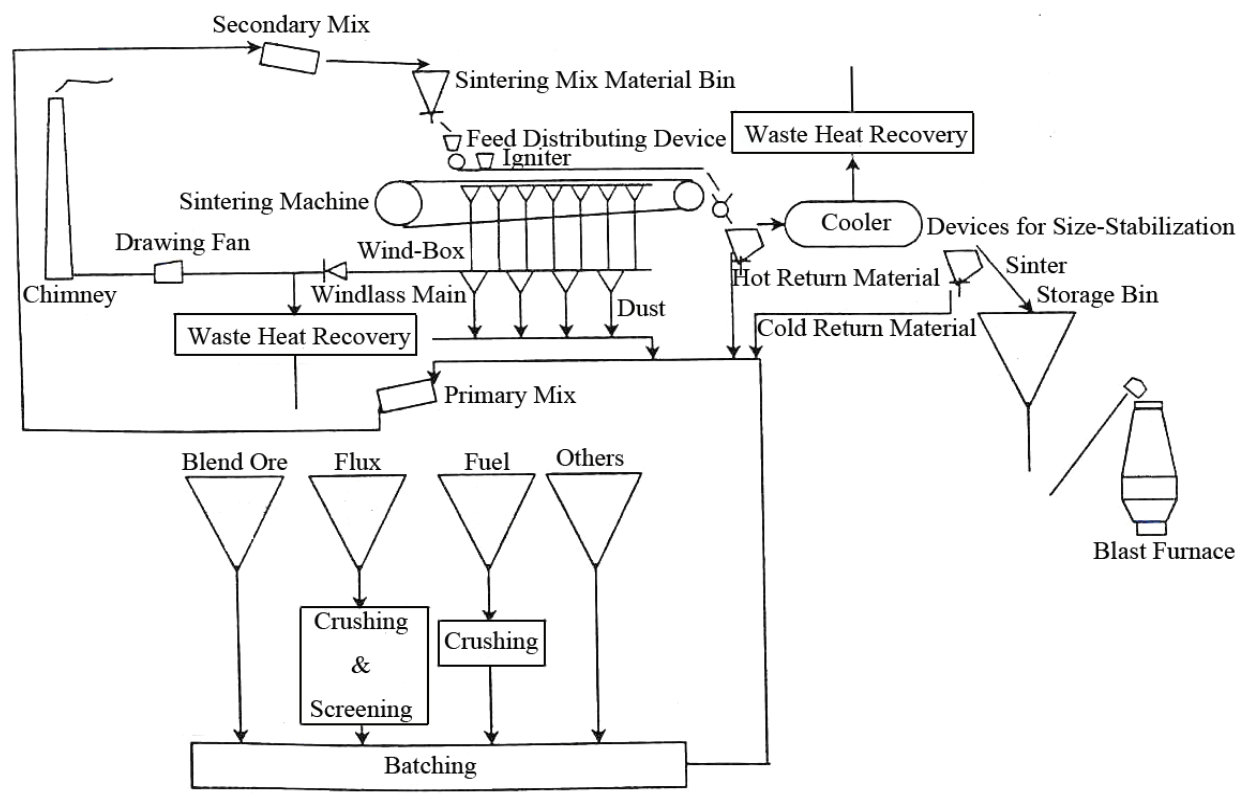

Fig. 1. Flowchart of sintering process

The purpose of computer control of sintering process is improving labor productivity, getting sinter with high yield and good quality, as well as saving energy. Application of computer control technology is a main reason for production improvement of sintering. 
Effect of computer control technique on sintering process becomes increasingly remarkable along with the scaling-up of sintering equipment and requirement upgrade of sinter quality by blast furnace.

Computer control technology for sintering process developed along with sintering technology. Computers began to be used for detecting, alarming, recording, printing, etc. in sintering process in the early 1960s in America and European countries represent by France and Belgium. Later, computers were used for open and closed loop control step by step. The developing center of computer control for sintering process gradually shifted to Japan in the 1970s. Many mathematical models and control systems, as well as advanced testing equipments like material level instrument, device for continuous measurement of permeability, infrared moisture analyzer, etc. were developed successively by large-scale iron and steel enterprises represented by Nippon Steel Corporation, Kawasaki Steel, NKK and Kobe Steel. These companies focused on the overall management automation later, to achieve third-level computer control by combination of management information system automation and manufacturing process automation. Meanwhile, Distributed Control System (DCS) was built up. DCS was applied in Japanese factories such as Mizushima Factory and Chiba Factory of Kawasaki Steel, as well as Muroran Factory and Nagoya Factory of Nippon Steel Corporation (Ma, 2005).

Third-level computer control system includes Digital Control System, Process Computer System (PCS) and Central Computer System (CCS). Its function rating is shown in Fig. 2 (Unaki et al., 1986).

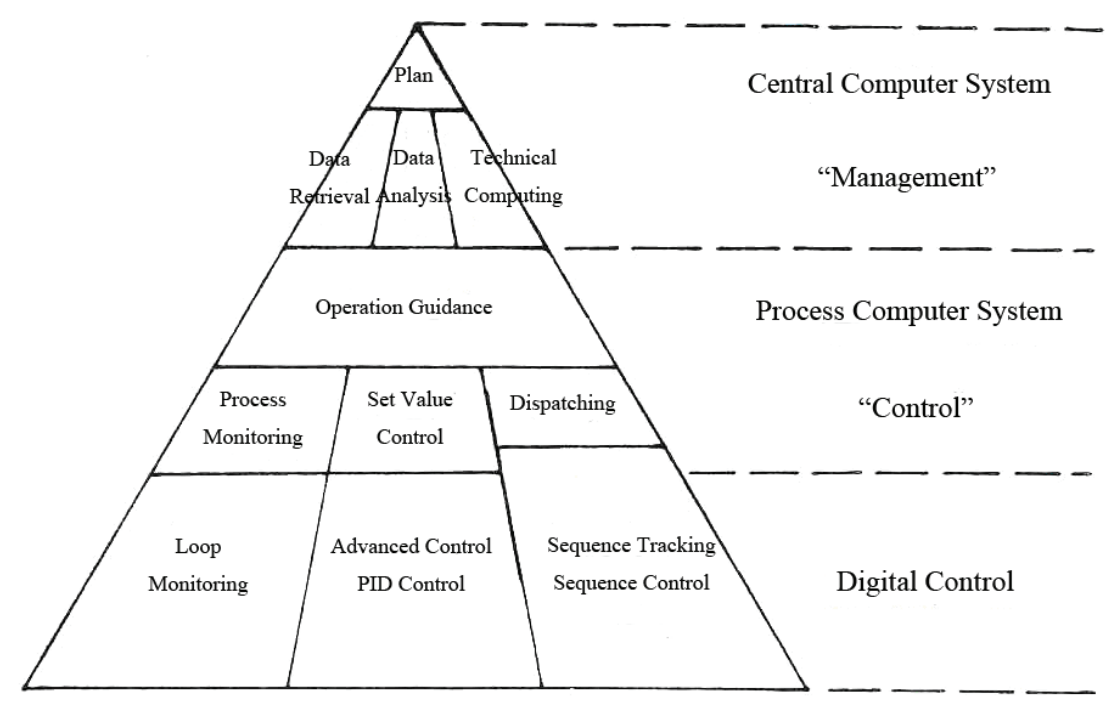

Fig. 2. Function diagram of third-level control system of sintering process

Digital control system is an integrated monitoring and control system. It includes direct digital control computers, sensors and transmission devices. It gives local loop control and advanced control of process with a standard of set value of process computer. Moreover, it takes real-time monitoring on sintering process based on sensor information as exhaust gas temperature, air displacement, etc. 
The functions of sintering process computer system is collecting and processing data sent by digital control system, increasing the operation efficiency of equipments, realizing set value control and comprehensive operation guidance of sintering process based on the operation plan made by central computer.

Central computer locates on the top level of the system. It possesses databases of the whole ironmaking system. Central computer is in charge of collection and stockage of information sent by subordinate computers. It gives material purchasing and production planning, makes production report and technical analysis of production data.

This control system can overcome the obstacles of unicity and limitation of analog instrumentation, and avoid fatalness of highly concentrated computer control. It has flexibility structure, facilitative expansion and high reliability. It is a significant trend in the development of large-scale computer control system (CHEN, 1990).

From the mid-1980s, artificial intelligence technologies, especially expert system were applied into sintering, preceding by Kawasaki Steel in Japan. Thus control reliability and precision were greatly improved. During this time, America and Canada put a lot of effort into the development of measure equipment and mathematical model, and great progress was made.

With the application of third-level control system in Kawasaki Steel of Japan, human resources were saved, operation costs were reduced, and operation management level was increased (Unaki et al, 1986). NKK declared to have their No. 4 sintering machine in Fukuyama Factory to be the first unmanned operation sintering machine in the world. At present, Australia, Germany, France, England, Finland, Sweden, Italy and Korea have also reached great height of computer control level of sintering process.

A striking feature of the progress made by sintering process technology in China is the widespread use of computer control system since the 1980s. And artificial intelligence has been used in sintering production since the 1990s Researches and applications are mostly in expert system. At present, successful research results include expert systems for sintering process control developed by author in Anshan Iron \& Steel, Wuhan Iron \& Steel, Panzhihua Iron \& Steel and Baosteel. This expert system consists of subsystems including expert system for chemical composition control of sinter, permeability control, thermal control and abnormity diagnosis of sintering process.

\section{Characteristics and control schemes of sintering process}

\subsection{Characteristics of sintering process}

The characteristics of sintering process resulting from characteristics of sintering technology and mechanisms of sintering process is as follow:

1. Large hysteresis

Raw materials to become sinter cake through batching, mix-granulation, feeding, ignition and sintering, and then Sinter production can be yield after procedures like hot crushing, hot screening, cooling and size-stabilization. And this process will take about two hours. Moreover, sinter yield and quality can be acquired by testing, which is usually taken out every 2 hours and last for about 1 2 hours in Chinese sintering plants.

Therefore, operating states of batching, mix and feeding before sintering can be reflected by sinter yield and quality after 3 5 hours. In other words, fluctuation of sinter yield and quality at present is caused by operations 3 5 hours ago. On the one hand, hysteresis of sintering process makes it hard to achieve accurate control; on the other hand, it causes 
fluctuations of sintering process. This is one of the key problems for accurate control of sintering production.

2. Complexity

(1) Complexity of mechanism

Sintering includes processes as combustion of fuel, heat exchange in sintering bed, evaporation and condensation of moisture, decomposition of chemical water, decomposition of carbonates, decomposition, reduction and reoxidation of oxides, solid state reaction, formation and condensation of liquid state during sintering process; theoretical foundation as thermodynamics, dynamics, heat transfer, hydrodynamics and crystalline-mineralogy, etc. Therefore, mechanism of sintering process is complex.

(2) Complexity of effect factors

From the process control point of view, sintering is a system as follow: certain material parameters and operating parameters act on device parameters (collectively referred to as "technological parameters"), then there are corresponding state parameters and index parameters. The model is shown in Fig. 3.

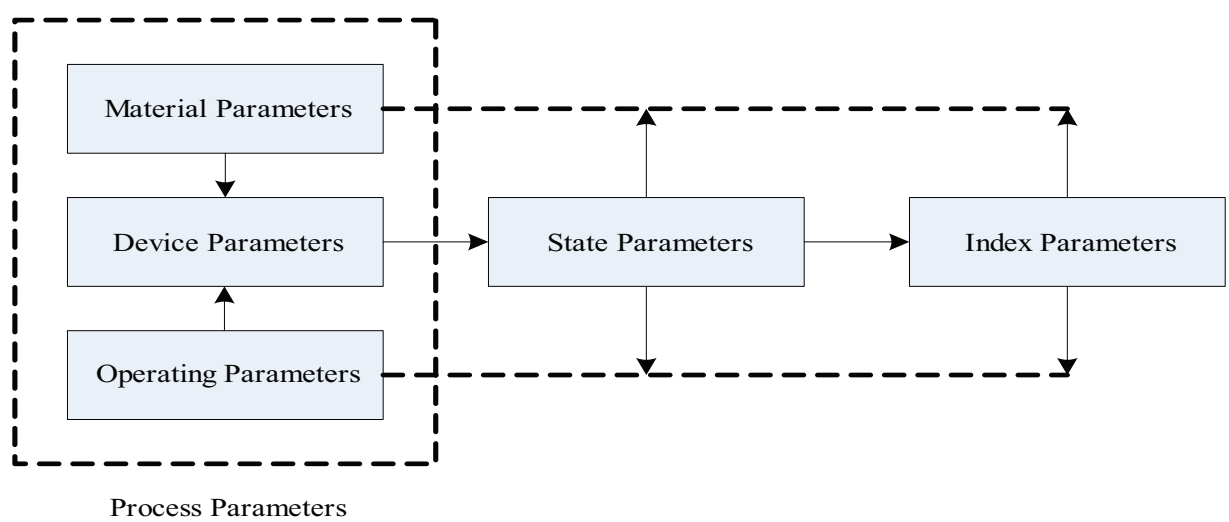

Fig. 3. Model diagram of sintering process

The complexity of effect factors of sintering process is reflected by the total amount of parameters in the five classes above and the correlation of them. Moreover, mutual restraint exists among effect factors of sintering process and quality indicators of sinter are closely related.

3. Dynamic time-varying

Sintering process is a complex industrial process which has the characteristics of continuity, nonlinear, time-varying and uncertainty besides complexity and large hysteresis.

\subsection{Control schemes of sintering process}

For a long time, sintering process is controlled with experience of operators to a large extent. The foundation of sintering process control is large amounts of real-time production data. Fluctuations of operation control which are adverse for production is inevitable because of hysteresis and fluctuations of data acquisition and detection, difference of operational knowledge, judgment-making ability, responsibility among operators, and other effect factors like physiological factors, psychological factors and environmental factors. This 
impact gets even bigger along with the scale-up of sintering machine. Meanwhile, it is hard to seize the opportunity to cut down the cost resulting from blind monitoring. Therefore, it is necessary to develop artificial intelligence control system of sintering process for the standardization and automation, further more, optimization of sinter production.

The necessity of index parameter prediction is decided by the large hysteresis of sintering process. For example, the large hysteresis of index parameters like chemical composition of sinter can be avoided by chemical composition prediction given by mathematical model of sinter chemical composition and material parameters, as material parameters are its main effect factors.

Applications of mathematical models in full-process control are limited because of the complexity of sintering process: mathematical models are useless in some parts and not accurate in some other parts; complex process models can not be used in online control, while simplified models bring in unstability, especially under abnormal circumstances. However, control by experience of operators may probably causes unstability of operation. Therefore, the problems which are hard to be solved by mathematical models can be figured out by artificial intelligence control system of sintering which is built using experience from sintering experts. Meanwhile, fluctuations of operation and production caused by artificial work can be avoided by standardization of operation, so that optimal control can be realized. Therefore, the combination of mathematical model and artificial intelligence is a condign method for sintering process control.

The complexity of sintering process results in the complexity of control system. However, high solving speed is necessary for real-time control system. Therefore, the general approach does some decomposition on complex control problems.

From the process control point of view, the purpose of sintering is getting optimal index parameters and state parameters by adjusting material parameters, operating parameters and device parameters. State parameters reflect the state of sintering process, while index parameters are indicators of sinter yield and quality. Quality indicators include chemical composition, physical properties and metallurgical properties, while physical and metallurgical properties are controlled by adjusting sintering process state and reducing the fluctuation of intermediate operation indicators. Factors affecting yield indicators are mainly permeability of sintering process, product yield and sintering pallet speed which are related to state control of sintering process. Energy consumption of sintering is connected with consumption of solid fuel, thereby related to thermal state. Therefore, sintering process control can be divided into sinter chemical composition control and sintering process state control as a whole. State control of sintering process mainly includes permeability state control and thermal state control.

\section{Construction of sintering process expert system}

\subsection{Overall construction of expert system}

Overall construction of sintering process control expert system is shown in Fig. 4.

Collect data required by system based on monitoring point of PLC, as well as data situation of distributed control system and factory LAN. After pre-processing, read these data in databases (multiple databases, easy to read and find). First, perform abnormity diagnosis: if it is only data exception, do optimal control after data processing; if it is production abnormity (including equipment overhaul, disorderly closedown, equipment failure, etc.), the system throws up alerts and corresponding suggestion. Then get into subsystems, and perform optimal control guidance at each of their own cycles. 


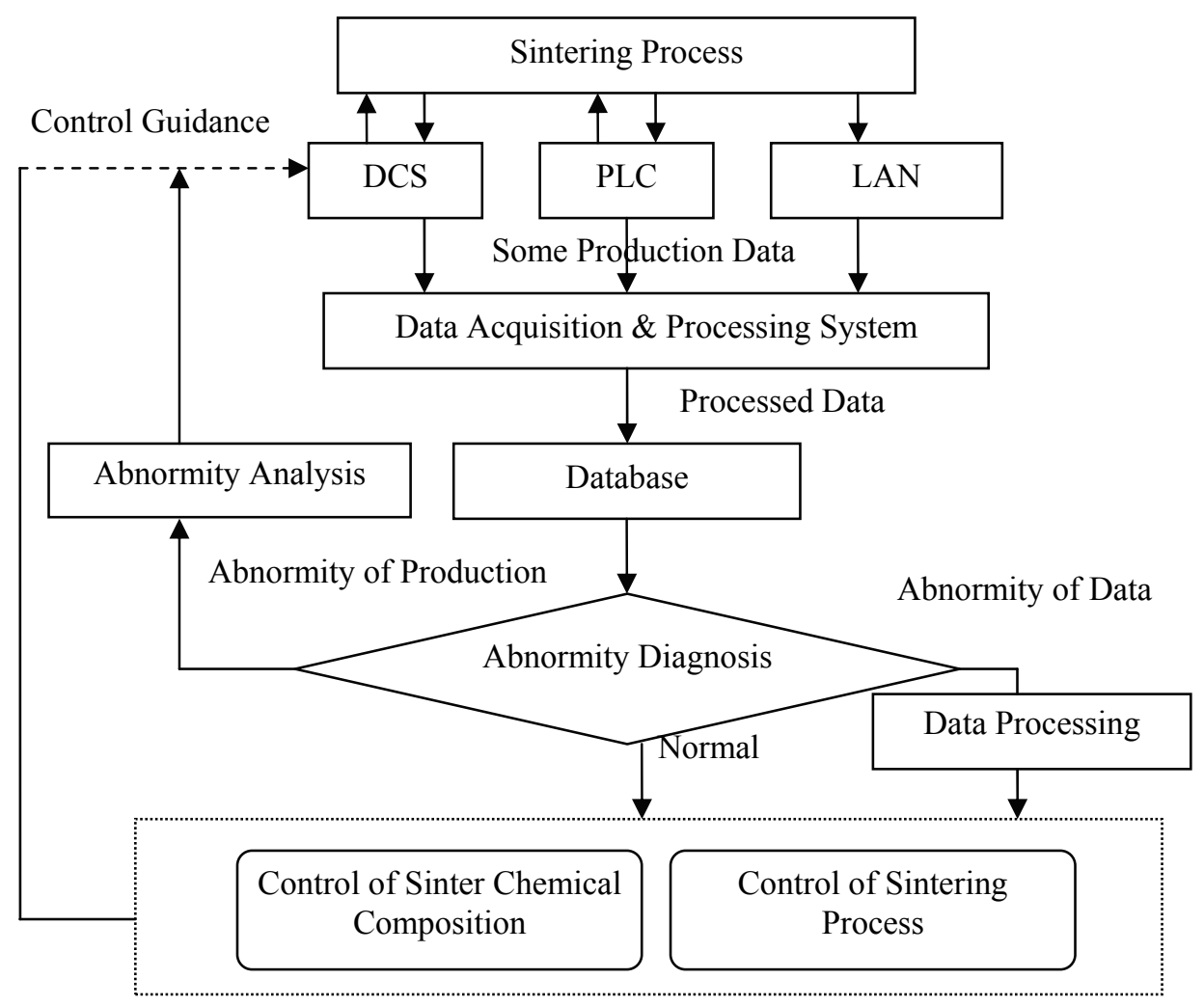

Fig. 4. Overall construction of sintering process expert system

\subsection{Characteristics and description of sintering process knowledge}

Knowledge of sintering process control includes five types: production data, facts, mathematical models, heuristic knowledge and meta-knowledge.

1. Production data

Production data is the starting point of sintering process control. In some reasoning process, such as basicity of sinter, burning through point, etc, production data of several moments is needed. While in some others, such as $\mathrm{TFe}, \mathrm{SiO}_{2}$ and $\mathrm{CaO}$ content of sinter, negative pressure of main pipeline, layer thickness, and production data in the present moment is the only requirement. Correspondingly, these two types of data can be defined as time-data and non-time-data. Predicate logic is used as a unified description:

$$
\text { predicate name ( object } 1,<\ldots, \text { object } n>,<\text { time }>\text {, value) }
$$

where: $\langle\ldots\rangle$ is optional, followed the same.

\section{Facts}

Facts include dynamic facts which reflect production state, and static facts which reflect characteristics of technology, production requirements, and reasoning services for system. Among these dynamic and static facts, some of them are only qualitative or quantitative descriptions, like "limestone flow is heavy", "1-step of layer thickness adjustment is $10 \mathrm{~mm}$ ", 
etc; while some others also need to start certain process, some fact-description code or something. Therefore, facts are expressed in the unified form of predicate logic as follow:

$$
\text { predicate name ( description } 1,<\ldots \text {, description } \mathrm{n}>,<\text { table }>,<\text { value }>\text { ) }
$$

3. Mathematical models

Mathematical models are consists of time-invariant models with unchanged coefficient and time-varying models with time-changing coefficient. Whichever they are, they are descriptions of model solution which is a method of process representation. The reasoning process is efficient as in every single process, problem-solving is running into a fixed direction according to the order of embedded programs, and there is no need to match or select irrelevant knowledge. The efficiency is particularly outstanding for real-time identification needed timevarying models. Process expression of mathematical models is as follow:

$$
\text { process name ( <code>, < variable }>\text { ): - procedure body. }
$$

Other process can be called by procedure body.

Some quantitative calculation is required during inference process from time to time. Thus, model code is stored in heuristic knowledge rules. During solving process, appropriate model is adopted for quantitative calculation based on inference conditions.

4. Heuristic knowledge

Heuristic knowledge is a kind of empirical knowledge accumulated by sintering experts from long-term production practices. It is mainly used for state judgment, cause analysis and control guidance. The process of judgment, analysis and guidance is in the form of production rule, i.e. conclusions come from corresponding conditions. Thus, heuristic knowledge is mainly described by production rule. Heuristic knowledge has the following features: there are calls between rule and rule or rule and process; the condition part of rule includes both facts and production data; there are rules and code for other rules or process in the conclusion part. Therefore, heuristic knowledge is described by the combination of production rule, predicate logic and process. Its general form is as follow:

$$
\text { rule name (rule ID, condition part, conclusion part) }
$$

\section{Meta-knowledge}

Meta-knowledge is mainly used to decide the solve order of sub-tasks, and give out the solving strategy knowledge base names needed by each sub-task. Moreover, it is used to call the initial facts before solving sub-tasks and store the conclusions after that. The coordination of each sub-task is also accomplished by meta-knowledge. Process representation method is used for the description of meta-knowledge.

Diversity and complexity of sintering process control knowledge lead to the incompetence of single knowledge representation. Therefore, a hybrid knowledge representation model which is the combination of production rule, predicate logic and procedural representation is adopted. This hybrid system results in the multi base structure of knowledge base management.

\subsection{Management of sintering process knowledge base}

\section{Multi-database structure}

Knowledge base of sintering process has a structure of four-base-group which is consisted of data base, fact base, model base and rule base, which is shown in Fig. 5 . 


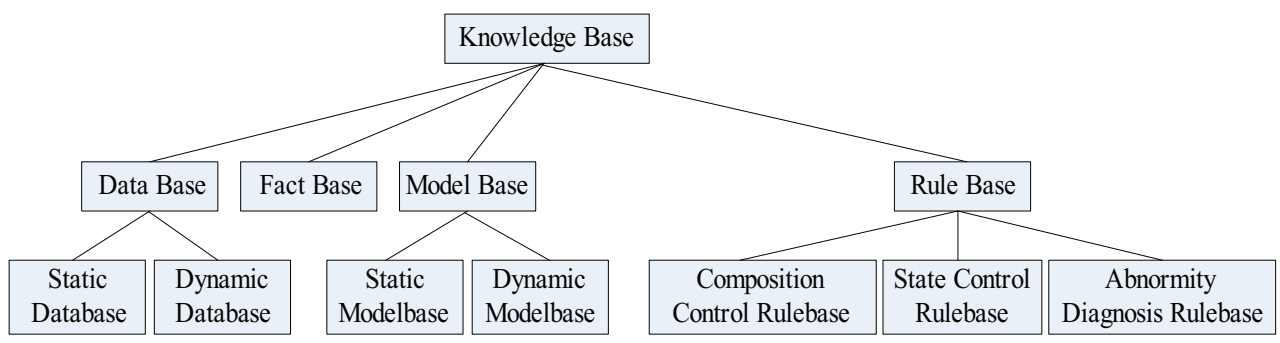

Fig. 5. Multi database structure of knowledge base

For relationship with time, production data and facts are divided into three types, real-time dynamic data and facts, slow-time-varying (i.e. data changes at regular intervals) and timeinvariant static data and facts. Dynamic data and facts data are directly stored in internal dynamic database, i.e. blackboard, for the convenience of inference. While data of the other two types is stored in external database. Likely, there are two types of mathematical models, time-invariant model and time-varying model. They are stored in static model library and dynamic model library separately.

Rule base is used for the storage of heuristic knowledge. Sintering process control expert system is consisted of sub-systems such as composition control system, state control system, abnormity diagnosis system, etc. For the convenience of inference, corresponding rule base is divided.

2. Hierarchy of rule base

To narrow the search, and improve reasoning speed, groupings of rules in every rule base are established. For example, rules of process state control are divided into four groups based on the difference of tasks: group of state judgment rules, group of state prediction rules, group of cause analysis rules, group of control guidance rules. Expressed in the form of: Rules for State Judgment: [data] $\rightarrow$ state judgment

Rules for State Prediction: [state 1, state $2, \ldots$, state $n] \rightarrow$ state prediction

Rules for Cause Analysis: [state 1 , state $2, \ldots$, state $n,<$ state prediction $>$ ] $\rightarrow$ cause analysis

Rules for Control Guidance: [cause, state] $\rightarrow$ control guidance

Layers are based on the group number of rules above. Rules which share the same group number are in the same layer. Provides that the smaller group number is, the higher layer is. Meanwhile, scheduling rules are designed in every group. These rules call corresponding rule blocks according to prerequisite. Expressed as follow:

$[$ term $1, \ldots$, term $n] \rightarrow$ rule block

With applications of these rules, public use of condition part is realized, searching range is limited, and inference speed is accelerated.

\subsection{Inference engine}

Sintering process control expert system gives state judgments of parameters based on realtime production data; then analyzes their state and gives cause analysis; finally, gives control guidance based on these states and causes. Therefore, the reasoning process of sintering process control expert system is multi-level-objective.

Procedural inference is used for inference engine between three level targets: state judgment, cause analysis and control guidance. Inference engine prerequisites of each level are fully known and sufficient, thus forward inference is adopted. That means procedural 
inference engine is adopted by overall target while forward inference engine is adopted by each level target.

Therefore, hybrid reasoning strategy which is a combination of forward reasoning and blackboard and procedural inference are adopted in this system. The inference engine structure is shown in Fig. 6.

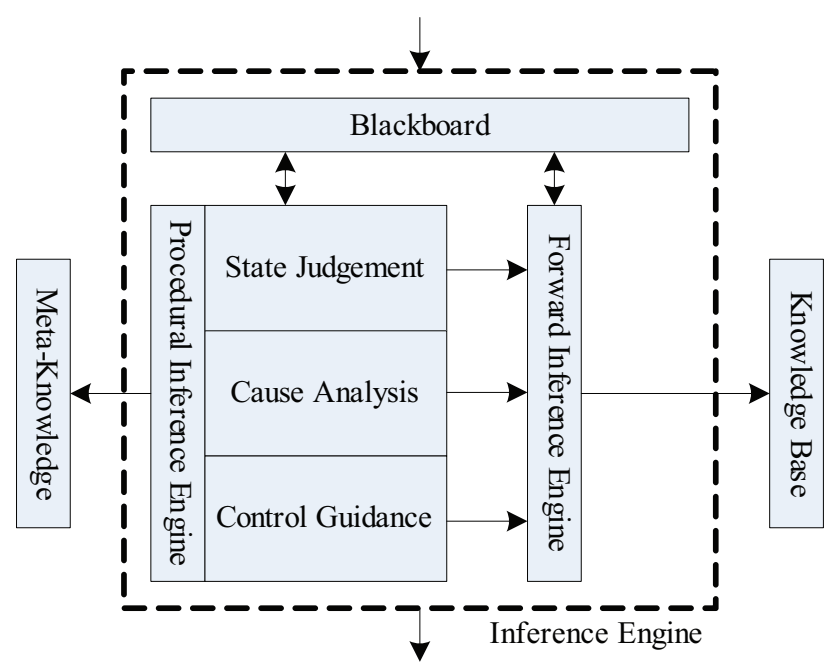

Fig. 6. Inference engine structure of sintering process control expert system

A new searching strategy is put forward according to the characteristics of the inference process. Characteristics of sintering process control inference are analyzed taking cause analysis of sinter chemical composition as an example.

Cause analyses of sinter chemical composition focus on R. R has five states, and it is in one state at each certain time. When $\mathrm{R}$ is in a certain state, TFe has five possible states. But TFe has only one state with specific production data at certain time. $\mathrm{SiO}_{2}, \mathrm{CaO}, \mathrm{MgO}$ and $\mathrm{FeO}$ are also the same. For example, the possible line of reasoning at certain time is as follow:

$$
(R)_{0} \rightarrow(\mathrm{TFe})_{-1} \rightarrow \cdots \rightarrow(\mathrm{MgO})_{0} \rightarrow \text { Reason } i
$$

Characteristics of inference process are as follow:

1. All nodes at the same layer share the same characteristics. But they are mutually exclusive. When one node succeeds, the others are defaulted to be failed.

2. "Repeat search" never happens.

This study proposes a search strategy named Finite-Breadth-First-Search, based on the characteristics above. The searching process is as follow: firstly, searching nodes in the first layer. As long as there is one node succeeds, other nodes in the same layer are defaulted to be failed whether they have been searched or not. Moreover, all branches of these failed nodes are defaulted to be failed. Then searching nodes in the next layer, and limiting the range to the branch nodes of the successful upper layer nodes. Other layers are the same. This method is called limited-breadth-first search strategy as it is equal to searching every node in every layer with breadth-first search, but with limit in the breadth of node. 


\section{Chemical composition control of sinter}

Chemical compositions of sinter include basicity (R), TFe, $\mathrm{SiO}_{2}, \mathrm{CaO}, \mathrm{MgO}, \mathrm{FeO}, \mathrm{P}, \mathrm{S}$, etc. Sticking point of chemical composition control of sinter is the stability of these compositions. Production practice home and abroad has proved that fluctuations of sinter chemical composition have great effect on blast furnace. When fluctuation of TFe content in sinter falls down from $\pm 1.0 \%$ to $\pm 0.5 \%$, yield of blast furnace generally increases by $1 \% \sim 3 \%$. When fluctuation of R falls down from \pm 0.1 to \pm 0.075 , yield of blast furnace increases by $1.5 \%$, and coke ratio reduces by $0.8 \%$. However, great fluctuation of sinter chemical composition is an outstanding issue of blast furnace both in China and abroad. Therefore, stability control of sinter chemical composition is significant.

Chemical composition control of sinter has the following characteristics:

(1) Stability of sinter chemical composition (except for FeO and S) is mostly affected by material parameters, while rarely by state parameters.

(2) It takes a few hours from raw material to sinter, till getting testing results of sinter chemical composition, i.e. there are great hysteresises in time.

(3) Sintering process has dynamic complexity and time-varying characteristics.

(4) There is great correlation between different chemical compositions of sinter.

(5) Chemical composition control of sinter is complex. An unqualified composition is not necessarily caused by change of its own, but possibly solved by another aspect.

Therefore, neural network prediction model for chemical composition of sinter is developed using control method combined mathematical models with knowledge models. The flowchart is shown in Fig. 7, where $u$ is input, $y$ is output, $u^{\prime}$ is input after data processing, $y^{\prime}$ is output after data processing. $\mathrm{y}^{\prime}$ is in a $2 \mathrm{~h}$ cycle corresponding with testing cycle of sinter chemical composition.

\subsection{Prediction models for chemical composition of sinter}

It can avoid the complicated process of mathematical model development and realize nonlinear mapping of input parameters and prediction value of chemical composition by using artificial neural networks into prediction of sinter chemical composition. Dynamic changes of system can be tracked because of the adaptive character and self-learning ability of neural network.

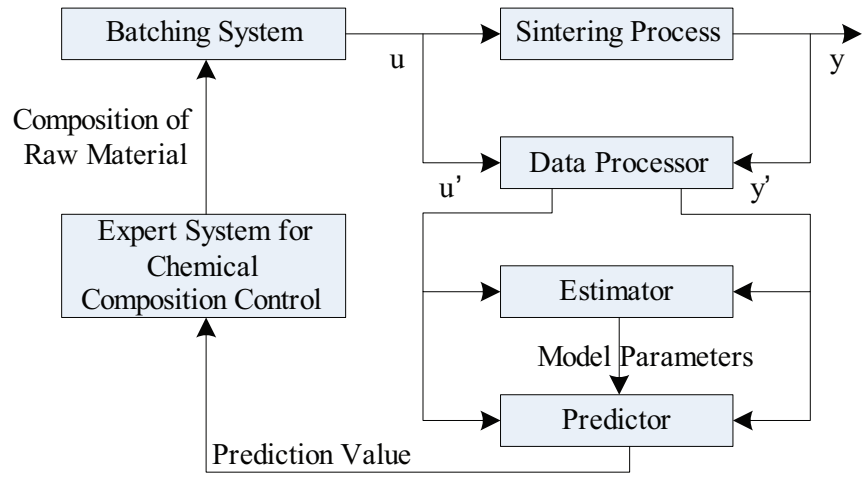

Fig. 7. Flowchart of chemical composition expert system based on prediction 
Rapid BP algorithm with adaptive variable step-size via linear reinforcement is adopted based on research of neural network models and their algorithms:

$$
\Delta \beta(\mathrm{t})=\varepsilon \lambda \beta(\mathrm{t}-1)
$$

Where $0 \leq \varepsilon \leq 1$ is constant, with a general value of $\varepsilon=0.20 \sim 0.30$. And the definition of $\lambda$ is as follow:

$$
\lambda=\operatorname{sgn}\left(\frac{\partial \mathrm{E}}{\partial \mathrm{W}(\mathrm{t})} \cdot \frac{\partial \mathrm{E}}{\partial \mathrm{W}(\mathrm{t}-1)}\right)
$$

Then BP algorithm turns into the form below:

$$
\mathrm{W}(\mathrm{t}+1)=\mathrm{W}(\mathrm{t})-\beta(\mathrm{t}) \frac{\partial \mathrm{E}}{\partial W(t)}
$$

Using Rapid BP Algorithm with Momentum Term and Adaptive Variable Step-Size:

$$
\begin{aligned}
& \mathrm{W}(\mathrm{t}+1)=\mathrm{W}(\mathrm{t})-\beta(\mathrm{t}) \mathrm{Z}(\mathrm{t}) \\
& \mathrm{Z}(\mathrm{t})=\frac{\partial \mathrm{E}}{\partial \mathrm{W}(t)}+\alpha \mathrm{Z}(t-1)
\end{aligned}
$$

In this formula: $0<\alpha<1$ is momentum factor; $0<\beta<1$ is learning factor.

The neural network model above is available to predict after training for systems which are stable and non-time-varying. However, adaptive update of prediction model for sinter chemical composition is demanded during the process of using because sintering is a timevarying process. The most commonly used adaptive method is equal dimension and new information method which is adding latest data into training sample set, deleting the oldest sample, and keeping unchanged sample amount, i.e. adaptive update for one time. Training of neural network runs in the background.

Parameters of online learning are as follow: 80 groups of training samples; momentum factor $\alpha=0.30$; initial rate of learning $\beta=0.70$; initial weight and initial threshold are both 0.50; excitation function is $f(x)=\frac{2}{1+e^{-x}}-1$. Using Rapid BP Algorithm with Momentum Term and Adaptive Variable Step-Size via Linear Reinforcement, adjustment of weight moves towards the average at the bottom without great fluctuation. When the system is in the flat area of function surface, the error is really small, thus $\Delta W(t+1)$ is almost equal to $\Delta W(t)$ and the average of $\Delta W$ becomes $\Delta W \approx \frac{-\beta}{1-\alpha} \bullet \frac{\partial E}{\partial W}$, where $\frac{-\beta}{1-\alpha}$ gets more efficient that the adjustment can get out of saturation zone as soon as possible. The problem of low learning efficiency and easy to converge at local minimum can be solved. When the training step reaches 6000 , training error of network is 0.000145 after online training the model onsite. Compared with general BP models, this model has faster rate of convergence which not only reduces the training time and guarantees the prediction accuracy, but also limits the oscillation and divergence. The error descending curves are compared in Fig. 8. 


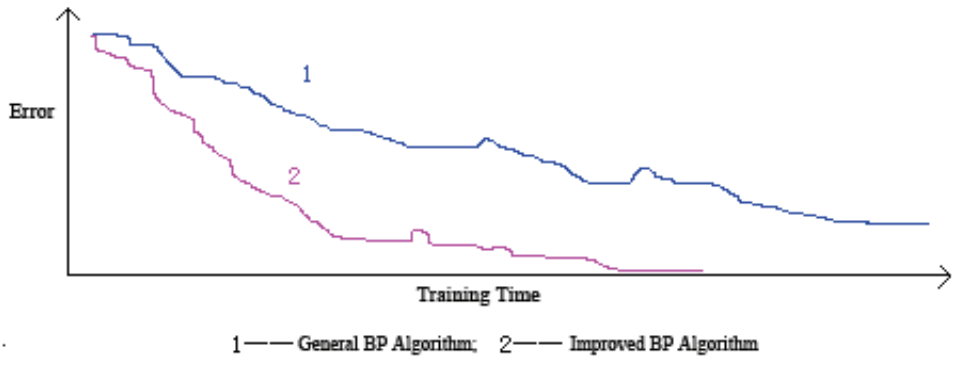

Fig. 8. Training error tendency of model

\subsection{Expert system for chemical composition control of sinter}

1. Control strategy of interval optimization

Point optimization which is unattainable because of characteristics of sintering process control is a control strategy aims at optimal point.

(1) Foundation of sintering process control is large amounts of real-time production data. Point optimization is hard to achieve because of the error between true value and detection value which is affected by noises and unmeasurable disturbances.

(2) Point optimization will result in frequent adjustment. Because of detection error and hysteresis of sintering process, frequent adjustments will cause large fluctuations of production. As a result, optimal control will be ruined as well as normal running of sintering process.

Relative to point optimization, interval optimization is a control strategy aims at optimal interval around optimal point. And interval optimization is a proper control strategy for sintering process control.

(1) Interval optimization aims at optimal interval. It can reduce inaccuracies caused by data measurement and avoid frequent adjustments of process control, so that stable operation of sintering process can be achieved.

(2) There are errors (within the allowable range) between prediction value and detection values of production parameters. Interval optimization can reduce misoperations caused by these errors.

Therefore, interval optimization is the control strategy adopted by this system.

Optimization of sintering process is based on normal running of sinter production, making judgments according to real-time detection value of production parameters. Therefore, values of production parameters can be divided into three intervals: optimal interval (marked as 0), feasible interval (interval between upper limit of optimal interval and upper limit of feasible interval is marked as +1 , while interval between lower limit of optimal interval and lower limit of feasible interval is marked as -1 ), and abnormal interval (interval over upper limit of feasible interval is marked as +2 , while interval under lower limit of feasible interval is marked as -2), shown in Fig. 9. The aim of interval optimization is getting optimal interval with feasible interval.

(1) Determination of Optimal Point

Optimal point is value of sintering process control object that meets requirement of process optimization. For sinter chemical composition, optimal point is standard of each 


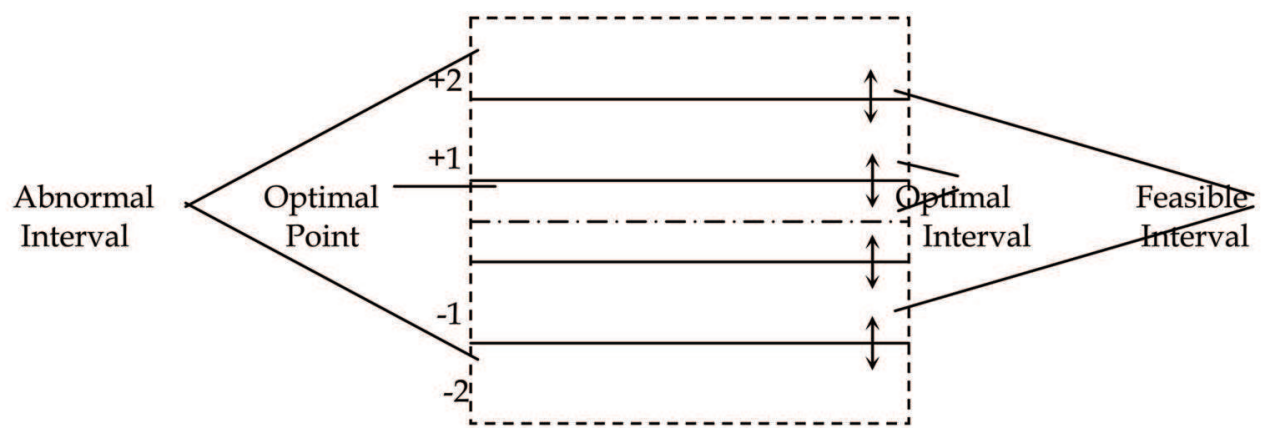

Fig. 9. Division chart of parameter interval

$\leftrightarrow$ variable boundary points

composition. For state parameters of sintering process, optimal point is determined according to the specific process and production conditions. For example, negative pressure of main pipeline is related to thickness of bed: the thicker bed is, the higher optimal value of main pipeline negative pressure is.

(2) Determination of Interval Boundary

Interval boundaries are critical points divided different intervals. Interval boundaries of sinter chemical compositions are based on the standards of first-grade, acceptable and defective products. For example: first-grade products specify TFe fluctuation in the range of $\pm 0.50 \%$; acceptable products specify TFe fluctuation in the range of $\pm 0.75 \%$; defective products specify TFe fluctuation in the range of $\pm 0.75 \%$. Therefore, interval boundaries of TFe are $+0.5 \%,-0.5 \%,+0.75 \%,-0.75 \%$.

(3) Description of State Parameter

+1 and -1 represent two different production states while value of parameter is in feasible interval. Similarly, +2 and -2 are two production states as well. Divide each production parameter into 5 states in order to make production state judgment accurately with real-time data of production parameter, and realize interval optimization. Taking TFe as an example, its state descriptions are shown in Table 1.

\begin{tabular}{cccccc}
\hline Interval Code & +2 & +1 & 0 & -1 & -2 \\
\hline $\begin{array}{c}\text { State } \\
\text { Description }\end{array}$ & too high & high & proper & low & too low \\
Interval Range & $>+0.75$ & $+0.75 \sim+0.5$ & $+0.5 \sim-0.5$ & $-0.5 \sim-0.75$ & $<-0.75$ \\
\hline
\end{tabular}

Table 1. State description of sinter chemical composition TFe

The purpose of interval optimization is realizing high-quality, high-yield and low-energy consumption by control of sintering process so that control variables are kept in optimal intervals.

2. Optimization strategy for sinter chemical composition

Synchronized optimization of each chemical compositions of sinter is optimal. However, the control strategy of "Synchronized Optimization" can hardly be achieved because of the great dependency of each chemical composition and randomicity of their changes. Therefore, sinter chemical composition control should lay emphasis on keystone. 
Stableness of each composition is main point of sinter chemical composition control. The small fluctuation range is, the better. Chemical composition control of sinter focuses on $\mathrm{R}$ and TFe control, as their fluctuations can result in fluctuations of blast furnace state. As long as $\mathrm{R}$ and TFe meet the requirement, it is not necessary to make any adjustment, regardless of state of the other compositions. While adjustment must be made if $\mathrm{R}$ and TFe are unacceptable, even if requirements of the other composition are satisfied.

To realize the optimization of $\mathrm{R}$ and $\mathrm{TFe}$, avoiding great fluctuations, as well as reducing the influence of prediction error, adjustments are made based on the state and changing tendency (past value, present value and future value) of $R$ and TFe.

(1) R is too high (or too low) \& TFe is too high (or too low): Adjust R and TFe regardless of state of the other compositions.

(2) $\mathrm{R}$ is too high (or too low) \& TFe is high (or low): Focus on the adjustment of R. Adjustment of TFe is based on its changing tendency. If the prediction value, present value and past value share the same changing tendency, adjust TFe. Or else, do not make any adjustment temporarily.

(3) R is too high (or too low) \& TFe is proper: Focus on the adjustment of R.

(4) $\mathrm{R}$ is high (or low) \& TFe is too high (or too low): Focus on the adjustment of TFe. Adjustment of $\mathrm{R}$ is based on its changing tendency.

(5) $\mathrm{R}$ is high (or low) \& TFe is high (or low): Adjustments of R and TFe are based on their changing tendency, respectively.

(6) $\mathrm{R}$ is high (or low) \& TFe is proper: Adjustment of R is based on its changing tendency.

(7) $\mathrm{R}$ is proper \& TFe is too high (or too low): Focus on the adjustment of TFe.

(8) R is proper \& TFe is high (or low): Adjustment of TFe is based on its changing tendency.

(9) $\mathrm{R}$ is proper \& TFe is proper: Making no adjustment regardless of state of the other compositions.

\section{Permeability control of sintering process}

Permeability is the difficulty of gas passing through the solid bed. The fluctuation and change of gas are related to the processes of mass transfer, heat transfer and physicochemical reactions. Therefore, permeability of sintering bed plays a decisive role in smooth operation of sintering process, thus affects yield and quality of sinter.

Permeability is commonly referred to as permeability of mix bed and permeability of sintering process.

\subsection{Permeability control of mix material}

Permeability of mix material is the permeability of bed before ignition. It is decided by physical and chemical properties of raw materials, moisture, mix-granulation, feeding, etc. Therefore, permeability control of mix material is realized by feed-forward control of these factors above. And the key point is accurate detection.

Basic approach of continuous detection of permeability is blowing method, i.e. blowing compressed air into mix material and measuring the pressure and flow of it. Permeability J is calculated by the following equation:

$$
J=K Q / \sqrt{p}
$$

Where: 
Q- - air flow, $\mathrm{m}^{3} / \mathrm{h}$;

$\mathrm{p}--$ pressure of air, $\mathrm{MPa}$;

K--coefficient, $h \cdot m^{-3} \cdot(M P a)^{-\frac{1}{2}}$.

There are two specific methods. One method is as follow: hang a pipe to the feeding bin; blow compressed air into it; get permeability of mix material by testing the air flow (Fig. 10).

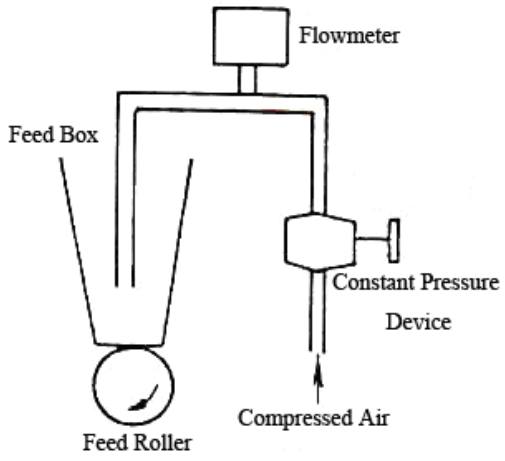

Fig. 10. Diagrammatic sketch of permeability detection

Another method is as follow: design a separate set of sampling devices; blow compressed air with constant pressure into a device full of mix material; measure the air flow; and the permeability is calculated based on the air flow. Compare two methods above, the former one has simple device structure, but with wind pipe easy to wear and clog. While the latter one has no wear and clog problems but its device structure is too complex.

In comprehensive simulation model of iron ore developed by Sumitomo Metals' Kashima Steel Works, permeability before sintering process is predicted by data of grain composition of raw material, granulation moisture, apparent density, etc (Takazo et al., 1987).

In process control model of sintering machine speed developed by Günther Straka from Austria, permeability of mix material can be calculated by the test data of waste gas flow, bed thickness and pressure difference in ignition hood. As well as the test data of air flow passing through bed (Straka, 1992).

\subsection{Permeability control of sintering process}

Permeability of sintering process is the permeability of bed after ignition. Along with sintering process, permeability of bed, which is one of the most important indicators for sintering operation, changes rapidly.

1. Operation Guidance System of sintering process

Kawasaki Steel Corporation in Japan developed Operation Guidance System for sintering process (OGS) in order to stable permeability of sintering process and sinter quality (Kazuma et al., 1987). Basic idea of OGS is shown in Fig. 11.

OGS consists of a main system and two subsystems. After inputting production data of sintering process into OGS, main system makes comprehensive assessment of permeability, sinter quality and productivity with decision making chart. And appropriate operation is chosen to meet the requirement of sinter yield and quality. One of these two subsystems is used to assess permeability, while the other is for auto-adjusting of the standard value for assessment. 


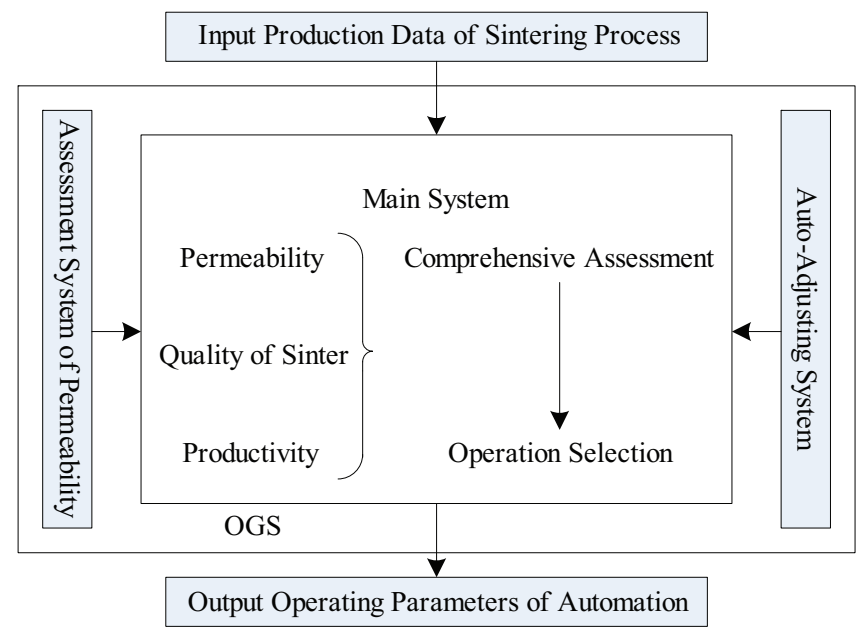

Fig. 11. Basic idea of OGS

Main system gives out the assessment by comparing 9 kinds of input data, such as permeability, productivity and quality, with the standard value of their 7 classes $(0, \pm 1, \pm 2$, $\pm 3)$.

Some of these standard values for process data assessment require adjustment from "AutoAdjusting System" every 30min. While other parameters, like main downdraught fan, which are not control objects, their standard values are from the average value, and their standard deviation is calculated by data collected in the past few hours.

$$
\text { standard value }=f(\bar{x}, \sigma)
$$

Where:

$\bar{x}--$ average value of process data collected in the scheduled past few hours;

$\sigma--$ standard deviation of process data collected in the same period with $\bar{x}$.

Productivity and quality which are control objects not auto-adjusting, as they have their own standards. They are set by operators based on operating conditions.

In order to reduce unit coke consumption, return material ratio and unit coke consumption are measured as they are closely related. And standard value of return material ratio is calculated.

Permeability of bed varies with parameters. Therefore, pressure of main downdraught fan, maximum temperature of wind-box, and burning through point are predicted and used for the assessment of permeability. Though their impact factors are multiple, the most important one is raw material permeability (RP). Therefore, autoregression models of the relationship between raw material permeability and these three parameters are developed respectively for the prediction.

Optimization of productivity and quality by operation adjustment is the main function of OGS. A three-dimensional diagram is used to making decisions of operating variables and range based on the assessment of permeability, return material ratio and productivity. Experience-based operating variables (sintering pallet speed, density of raw bed, and coke proportion) as well as 7-level operating range from -3 to +3 are set. 
2. Expert system for sintering process control centered on permeability

Fluctuations of sintering process are mainly caused by fluctuations of permeability. The state of permeability affects the stability of burning through point: with a too good permeability, burning through point is ahead of time; with a too bad permeability, burning through point is hysteretic. Thus stable and improve permeability of bed is the necessary way to stable burning through point, so that stability of sintering process can be achieved. Therefore, control of sintering process should center on permeability. Permeability-centered control strategy is as follow: when permeability is good, stable burning through point; when permeability is bad, improve permeability first, then consider keeping burning through point stable.

(1) Judging Method for Permeability of Sintering Process

Material parameters and operating parameters affect permeability of sintering process, while state parameters reflect it. When permeability is good, air is easy to pass through bed, so that air flow $(Q)$, vertical sintering speed $\left(V_{\perp}\right)$ and waste gas temperature $(T)$ increase, burning through point is ahead of time, negative pressure of main pipeline $(\Delta \mathrm{P})$ falls down; the reverse is true. Therefore, $\mathrm{Q}, \mathrm{V}_{\perp}, \mathrm{BTP}, \mathrm{T}$ and $\Delta \mathrm{P}$ reflect permeability from different aspects and are capable for the use of permeability assessment. However, $\mathrm{Q}$ is affected by air leakage rates beside permeability; fluctuation of T is mainly affected by BTP, as well as air leakage rates, season and carbon proportion. Therefore, they are not suitable parameters for permeability assessment.

BTP as a evaluation parameters of permeability has hysteresis in time, which is definitely going to affect the accurate judge of permeability and optimal control of sintering process. Therefore, prediction of BTP is necessary. Long-term production practices have proved that when sintering process is normal, BTP is stable, inflection point of wind-box temperature curve (called normal inflection point) located in a certain wind-box, and temperature of this wind-box (called normal inflection point temperature) is in a certain range; when BTP changes, normal inflection point temperature changes with it. Therefore, BTP prediction can be realized based on normal inflection point temperature and BTP state.

According to experience, permeability is good when vertical sintering speed $\left(\mathrm{V}_{\perp}\right)$ is high, prediction value of burning through point (BTP) is ahead of time, and negative pressure of main pipeline $(\Delta \mathrm{P})$ is low; while it is bad on the contrary. Rule base for permeability comprehensive assessment with prediction values of $\mathrm{V}_{\perp}, \mathrm{BTP}$, and $\Delta \mathrm{P}$ is developed based on this basic idea.

(2) Control Principle for Permeability of Sintering Process

With good permeability condition, burning through point is stabled by adjustment of sintering pallet speed and bed thickness. While with bad permeability condition, on the one hand, permeability has to be improved by controls of mix material moisture, mix material temperature, ignition temperature and coke proportion; on the other hand, burning through point has to be stabled by adjustment of sintering pallet speed and bed thickness.

Adjustment rules of sintering pallet speed and bed thickness are as follow: Focus on sintering pallet speed. Bed thickness has to be adjusted only if there are great changes for raw material and equipments.

\section{Thermal control of sintering process}

Temperature changes in sinter bed are the impetus of physical and chemical changes. Therefore, thermal state affects sintering process. 


\subsection{Thermal control based on BRP}

1. Calculation of BRP

Burning through point (BTP) is calculated with exhaust gas temperature of wind-boxes along the length of sintering machine. However, the accuracy of taking BTP as thermal state index is affected by air leak caused by shrinkage cracks of material bed and from discharge end of sinter machine. Therefore, a new index for thermal state of sintering process - BRP (Fig. 6-1) is brought forward by Keihin Steelworks of NKK (Michnori et al., 1992). It can be calculated by formula below:

$$
\begin{gathered}
G t_{k}=A x_{k}^{2}+B x_{k}+C \quad(\mathrm{k}=1 \sim 3) \\
A \cdot B R P_{t}^{2}+B \cdot B R P_{t}+C=t
\end{gathered}
$$

Where:

$\mathrm{BRP}_{\mathrm{t}}-$ Burning Rising Point;

$x-$ number of wind-box;

$\mathrm{Gt}$ - exhaust gas temperature below sintering pallet, ${ }^{\circ} \mathrm{C}$;

A, B, C-coefficient of exhaust gas temperature below sintering pallet along the length of sintering machine described by conic section;

$\mathrm{K}$-code of wind-box along the length of sintering machine (when $\mathrm{K}=1$, it is No. 18 windbox; when $\mathrm{K}=2$, it is No. 20 wind-box; when $\mathrm{K}=3$, it is No. 22 wind-box);

$\mathrm{t}$ - set temperature used for BRP calculation, ${ }^{\circ} \mathrm{C}$, set temperature $\mathrm{t}$ is the temperature of the center of temperature measuring position, i.e. almost equals to exhaust gas temperature of No. 20 wind-box, $\mathrm{t}=250^{\circ} \mathrm{C}$.

Fitting conic sections to exhaust gas temperature of the last a few wind-boxes (except the very last one). The position corresponding to a certain temperature on the curve is chosen as BRP. BRP is considered as target parameter of burning through point control so that effect of air leak at discharge end of sinter machine on exhaust gas temperature can be avoided.

Speed of sintering pallet is controlled by relation between sintering pallet speed and vertical position of $\mathrm{BRP}_{\mathrm{t}}$, so that position of $\mathrm{BRP}_{\mathrm{t}}$ along the length of sintering machine is stable.

2. Proposition and calculation of TRP

Exhaust gas temperature in wind-boxes from head to tail of sintering machine is studied. It is found that exhaust gas temperature curve is consistent with cyclic-n polynomial, as formula (6-3). And there is a strong-tie between temperature rising position and highest position. Therefore, Temperature Rising Position (TRP) is brought forward which is the position where temperature of exhaust gas in wind-boxes begins to rise (Fig. 12), as well as the position when mix material zone completely disappears. TRP is usually located at the mid-back part of sintering machine. There are not significant changes of exhaust gas temperature in the wind-boxes at the front part. And exhaust gas temperature rises rapidly after that.

$$
\mathrm{T}_{\mathrm{g}}=\mathrm{a}_{0}+\mathrm{a}_{1} \mathrm{X}+\mathrm{a}_{2} \mathrm{X}^{2}+\ldots \ldots+\mathrm{a}_{\mathrm{n}} \mathrm{X}^{\mathrm{n}}
$$

Where:

$\mathrm{T}_{\mathrm{g}}$ - exhaust gas temperature, ${ }^{\circ} \mathrm{C}$;

$\mathrm{X}$ - measuring position of exhaust gas temperature, $\mathrm{m}$;

$\mathrm{n}, \mathrm{a}-$ coefficients of polynomial. 


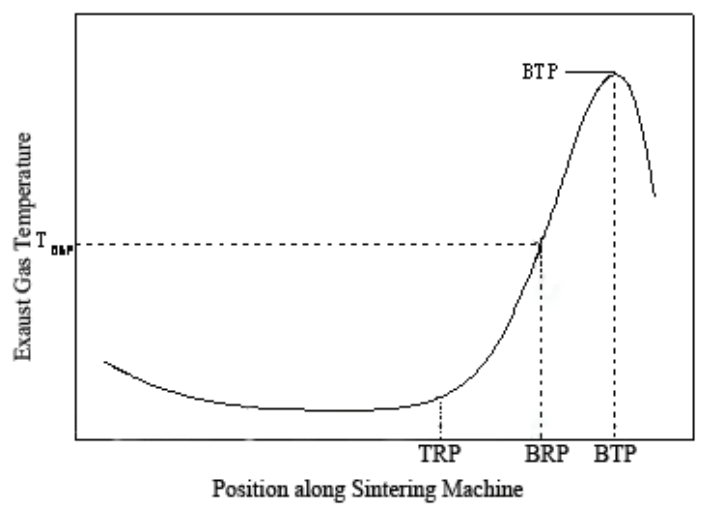

Fig. 12. Typical diagram of exhaust gas temperature curve

Measuring point data used for curve fitting is selected to avoid the effect of air leak at discharge end on exhaust gas temperature. Judgments of middle measuring point temperatures are made. If $\mathrm{T}\left(\mathrm{X}_{2}\right)-\mathrm{T}\left(\mathrm{X}_{1}\right)<\mathrm{T}_{\mathrm{c}}$, and $\mathrm{T}\left(\mathrm{X}_{3}\right)-\mathrm{T}\left(\mathrm{X}_{2}\right)>\mathrm{T}_{\mathrm{c}}, \mathrm{X}_{2}$ is centered; temperatures of 2 measuring points each side are taken; fit curve with these 5 temperature data; then real solution when slope of curve is 5 is considered as TRP temperature. $T_{c}$ is decided according to the condition of production, and it is generally $10 \sim 20^{\circ} \mathrm{C}$. Calculating range is set in $\left[X_{1}, X_{3}\right]$ according to the judgments above to get the TRP value fitting reality. Stability of BTP can be realized by stability of TRP, which is achieved by adjustment of sintering machine speed, with predictive fuzzy control method, making use of the relation between sintering machine speed and TRP position.

\subsection{BTP control based on combustion zone model}

\section{Combustion zone model}

BTP is decided by vertical velocity of combustion zone and horizontal velocity of sintering pallet in sintering process. And the main influencing factors of combustion zone are negative pressure of main downdraught fan and resistance of mix material (Fig.13). Therefore, combustion zone model (Straka, 1994) is as follow:

$$
\begin{gathered}
\frac{\mathrm{d}^{2} \mathrm{x}(\mathrm{t})}{\mathrm{dt}^{2}}=-\mathrm{A}+\mathrm{Bx}(\mathrm{t}) \\
\mathrm{x}(0)=\mathrm{H} \\
\frac{\mathrm{dx}(0)}{\mathrm{dt}}=0
\end{gathered}
$$

Where:

$x(t)$ - position of combustion zone;

$\mathrm{t}$-time ( $\mathrm{t}=0$ is the initial time);

A-pressure caused by main downdraught fan, which can be expressed by total flow of exhaust gas; 
$\mathrm{B}$-internal resistance of mix material, which is defined as a function of mix material permeability;

$\mathrm{H}--$ thickness of bed.

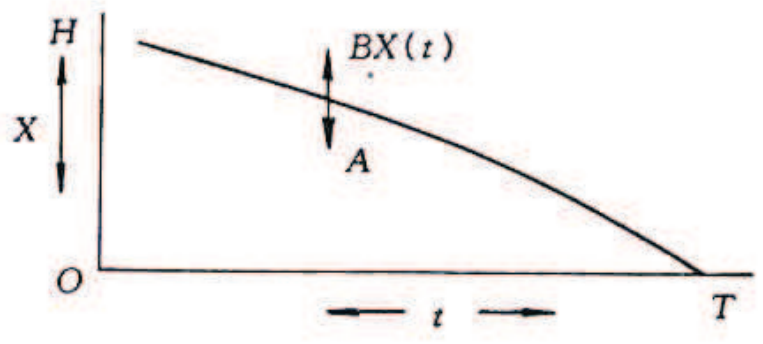

Fig. 13. Relation of combustion zone and time

2. Control model of sintering pallet speed

Control model of sintering pallet speed (Straka, 1994) is shown in Fig. 14.

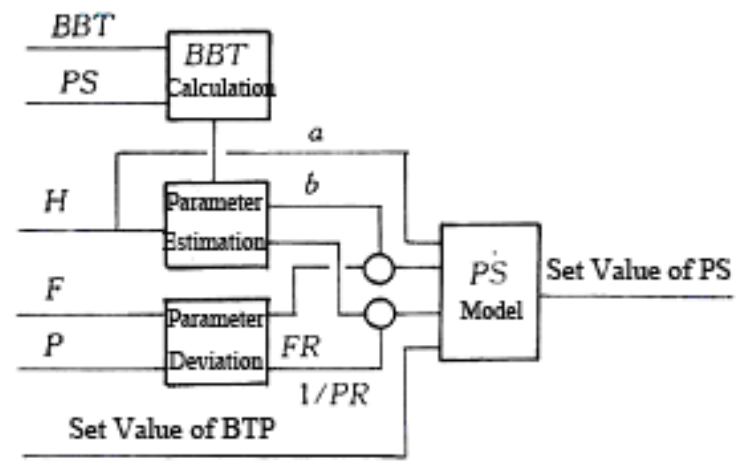

Fig. 14. Control model of sintering pallet speed

Burning through time (BTT) is calculated with BTP (which is calculated with detection value of exhaust gas temperature of wind-boxes) and sintering pallet speed (PS). Parameter a and $b$ are estimated online according to stable condition. Parameter deviation FR and PR are constant or slowly changing average. Calculate BTT of mix material just passed by ignitor. And set value of pallet speed can be calculated with the precalculated BTT and set value of BTP.

\subsection{Fuzzy control of BTP based on prediction}

\section{Prediction of BTP}

Estimate BTP with exhaust gas temperatures of the last few wind-boxes is time-lagging. And stability control of BTP, even the entire sintering process will be affected. Therefore, BTP prediction is necessary.

(1) Input parameters of prediction model

BTP prediction includes long-term prediction (about 30min) and short-term prediction (about 10min). Long-term prediction is BTP prediction based on permeability of raw material. And great external disturbance of raw material system such as changes of material 
proportion, segregation in material bins, changes of mix material moisture are the main considerations. Short-term prediction is BTP prediction based on temperature of BRP windbox. It has the qualities of short feedback time and high accuracy. Thus it is used when there are little external disturbance.

(2) Methods for modeling

Least-Squares Identification Method and BP Algorithm have their advantages and disadvantages over data processing of dynamic system. After these two methods were compared with large amount of industrial production data, Least-Squares Identification Method (FANG \& XIAO, 1988) is adopted by BTP predictions with short cycle. Initial values of model parameters are calculated by using 250 sets of production data. Then adaptiveness of model parameters is realized with recursive algorithm. Given the same confidence to former and latter data, data grows with time, information given by new data will be flooded by former data. Thus identification ability of the algorithm is lost, and "data saturation" happens. To solve this problem, identification algorithm is modified with method combines both ideas of forgetting factor and limited memory. Data length of identification keeps the same and forgetting factors are added to former data. The recurrence equation is shown in Formula (6-7). Forgetting factor $\mu$ is 0.98 .

$$
\begin{aligned}
& \hat{\theta}(k+1, k+L)=\hat{\theta}(k, k+L)-K(k+1, k+L)\left[y(k)-h^{\tau}(k) \hat{\theta}(k, k+L)\right] \\
& K(k+1, k+L)=P(k, k+L) h(k)\left[\mu^{-L}-h^{\tau}(k) P(k, k+L) h(k)\right]^{-1} \\
& P(k+1, k+L)=\mu^{L}\left[I+K(k+1, k+L) h^{\tau}(k)\right] P(k, k+L) \\
& \hat{\theta}(k, k+L)=\hat{\theta}(k, k+L-1)+K(k, k+L)\left[y(k+L)-h^{\tau}(k+L) \hat{\theta}(, k+L-1)\right] \\
& K(k, k+L)=P(k, k+L-1) h(k+L)\left[\mu+h^{\tau}(k+L) P(k, k+L-1) h(k+L)\right]^{-1} \\
& P(k, k+L)=\frac{1}{\mu}\left[I-K(k, k+L) h^{\tau}(k+L)\right] P(k, k+L-1)
\end{aligned}
$$

2. Fuzzy control of Burning Through Point

Sintering process is a complicated nonlinear system. Fuzzy control method which includes fuzzification, fuzzy inference and defuzzification is adopted. Deviation and deviation change of prediction position and set position of burning through point are considered as inputs while speed of sintering machine is output for the control of burning through point. The input and output are represented by 7 fuzzy variables expressed as $\{N B, N M, N S, Z R$, PS, PM, PB $\}$, and the numeral expression is $\{-3,-2,-1,0,1,2,3\}$. The ranges of fuzzy variables are all in $[-6,6]$ in order to insure that fuzzy set can cover the whole range. The membership function is isosceles triangle, and distributes symmetrically in the whole range. It is showed in Fig. 15.

Commonly used fuzzy inference methods at present include Max-Min Method and Maximum Product Method, etc. For fuzzy control rule $R_{i}$, total satisfaction of conditions is the minimum of sub-condition membership, as the sub-conditions are connected by "and" operator. In fuzzy logic, "if - then" relation can be expressed by cross product of conditions and conclusions. If the minimum value of conditions and conclusions membership function is taken for cross product membership function, it is Max-Min Method; if product of conditions and conclusions membership function is taken for cross product membership function, it is Maximum Product Method. Final output fuzzy variables are the summation of membership functions inferred by all the rules because the connecting operator between rule and rule is "or". And it shapes as a polygon. 


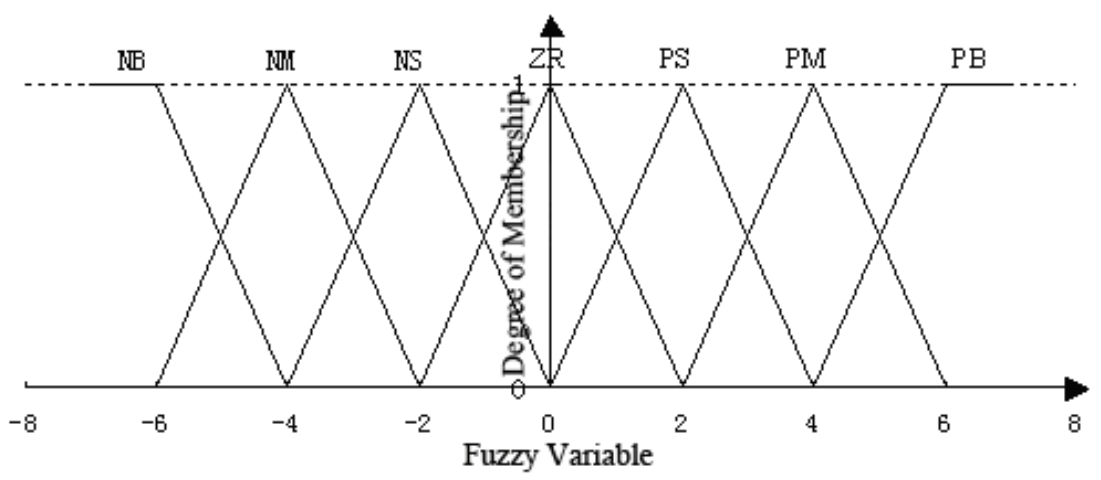

Fig. 15. Membership function of fuzzy controller

Defuzzification methods in common use include Maximum of Membership (MoM), Center of Gravity ( $\mathrm{CoG}$ ) and Center of Area (CoA). Values of MoM is relatively unilateral; calculation of CoA is more cumbersome, not easy-programming; while CoG covers all the possible values of output variables and is easy-programming. CoG also called as Weighted Average Method is similar to the calculation of gravity center (GUO et al., 1999). When the range is discrete:

$$
Z_{0}=\frac{\sum_{i=1}^{n} z_{i} \mu_{c^{\prime}}\left(z_{i}\right)}{\sum_{i=1}^{n} \mu_{c^{\prime}}\left(z_{i}\right)}
$$

Sintering is a time-varying process. Change of raw material structure will result in change of optimal range for sintering process parameters, as well as change of control object. Therefore, fuzzy control algorithm should be adaptive, track changes of system automatically, and makes corresponding adjustment. Control effect depends on number of fuzzy set, membership function and control rules after the input and output variables of fuzzy control algorithm as well as fuzzy inference and defuzzification method are determined. In author's research, non-linear quantitative curve and adaptive control rules are used to realized the adaptiveness of control algorithm.

\subsection{Control of BTP based on expert experience}

Control of BTP is included in Diagnosis Expert System of Sintering Operation developed by Mizushima factory of Kawasaki Steel (Fukagawa, et al. 1991). It consists of management of normal BTP and management of abnormal BTP.

1. Management of normal BTP

Management of normal BTP includes management of real BTP and management of predicted BTP. Predicted BTP is usually used for BTP management. Management of real BTP is required for control adjustment when real BTP is beyond the normal management range for reasons like sudden external interference. Prediction of BTP consists of long-term prediction and short-term prediction. And autoregression model is their common prediction method. When long-term prediction value of BTP is over upper limit of requirement, 
immediate operation to slow down pallet speed is demanded, in order to avoid not burning through caused by operation delay. When long-term prediction value of BTP is under upper limit of requirement, firing state is judged by short-term prediction value and real BTP. The judgments are expressed in 11 grades. In conclusion, changing sintering pallet speed is the measure that taken when BTP is in abnormal state.

2. Management of abnormal BTP

Equipments are protected from breakage and burn with process value monitoring. Diagnoses of operation state of cooling temperature, EP temperature and negative pressure of main fan are taken out by management of abnormal BTP in a $1 \mathrm{~min}$ cycle. When they are beyond the ratings, emergency measures of changing pallet speed or opening of main fan gate are taken. Then cause analyses of abnormities and operation guidance are given out. Opening of exhaust fan gate and pallet speed are back to normal according to real BTP state after eliminating the abnormities. Then it goes back to BTP management function.

\subsection{Control of thermal state based on energy consumption of sintering}

With certain mix material chemical composition, granularity and metallurgical properties, permeability of raw material is decided by mix material moisture, while permeability of sintering process which affects thermal state is decided by fuel ratio. Moreover, fuel ratio decides energy consumption of sintering process as well. Chiba Factory of Kawasaki Steel developed Sintering energy consumption control system (SECOS) (Sasaki, 1987) on No. 3 and No. 4 sintering machine. SECOS estimates energy fluctuations with RC and HZR, so that automatic control of coke ratio is achieved.

1. Calculation of RC

$\mathrm{RC}$ is equal to the carbon content calculated by concentration of $\mathrm{CO}$ and $\mathrm{CO}_{2}$ in exhaust gas and flow of exhaust gas, minus $\mathrm{CO}_{2}$ content produced by combustion of mixed-gas and decomposition of carbonate, then convert it into coke ratio, i.e.:

$$
R C=\left[V_{e x} \cdot\left(\mathrm{CO}+\mathrm{CO}_{2}\right)-V_{\mathrm{CaCO}_{3}}-V_{\text {Dolo }}-V_{\mathrm{MG}}\right] \times \frac{13}{22.4} \times \frac{1}{M \times F C} \times 100 \%
$$

Where:

$\mathrm{V}_{\mathrm{ex}}$-flow of exhaust gas (dry), $\mathrm{m}^{3} / \mathrm{h}$;

$\mathrm{V}_{\mathrm{MG}}-\mathrm{CO}_{2}$ amount produced by combustion of mixed-gas, $\mathrm{m}^{3} / \mathrm{h}$;

$\mathrm{CO}, \mathrm{CO}_{2}-$ concentration of $\mathrm{CO}$ and $\mathrm{CO}_{2}$ in exhaust gas; Sampling pipes are set at exhaust gas fan exit, considering the adverse effect of bias in gas collector and dust in exhaust gas.

$\mathrm{V}_{\mathrm{DOLO}}, V_{\mathrm{CaCO}_{3}}-\mathrm{CO}_{2}$ amount produced by thermal decomposition of dolomite and limestone, $\mathrm{m}^{3} / \mathrm{h}$; There is about $30 \mathrm{~min}$ of time lag from mix material discharges from material bins to testing results of exhaust gas composition is given out. Therefore, track time is required before using amount of dolomite and limestone in calculation.

$\mathrm{FC}--$ content of free carbon in coke, $\%$;

$\mathrm{M}--$ mix material consumption, $\mathrm{t} / \mathrm{h}$.

$$
M=P S \times H \times W \times \rho \times 60
$$

Where:

PS - - detection value of sintering machine speed, $\mathrm{m} / \mathrm{min}$;

$\mathrm{H}--$ detection value of sintering material thickness, $\mathrm{m}$;

$\mathrm{W}--$ width of sintering pallet, $\mathrm{m}$; 
$\rho--$ calculated value of mix material density on sintering machine, $\mathrm{m}^{3} / \mathrm{h}$.

2. Detection of HZR

Cross section of sinter cake which is about to falling is shot by monitor of industrial television (ITV) set at the discharge end of sintering machine. Image signals from the camera are presented on color monitor according to their temperatures after processed by image processing device and color simulation device. Meanwhile, hot zone (over $600^{\circ} \mathrm{C}$ ) area ratio (HZR) is isolated by image processing device. HZR is calculated with the unit of 1 second. Maximum value of each pallet is considered as the control value. And index selection processing is carried out with superior process computer.

3. Status evaluation and control of RC and HZR

$\mathrm{RC}$ and HZR are calculated every $5 \mathrm{~min}$. And sintering state is estimated by 7 grade $(0 \sim \pm 3)$ according to the deviation between calculated value and target value. Comprehensive evaluation of sintering heat level is given out based on separate evaluation results of RC and HZR. Amount and direction of coke adjustment is described by comprehensive evaluation $0 \sim \pm 3$. Adjusted value is adopted only if there are deviations for both RC and HZR. Suitable value of coke ratio is calculated based on result of comprehensive evaluation. And it is used as set value of coke supply of lower DDC.

\section{Conclusion}

Optimal control for sintering process can be divided into two types, based on mathematic model and artificial intelligence, by control methods. As it is too hard to describe the complicated mechanism of sintering process, Japan and some other countries with advanced iron \& steel industry made energetic efforts to develop artificial intelligence based control for sintering process and got some remarkable achievement in the late 1980s. In the late 1990s, advanced intelligent control systems are imported from abroad by some domestic large and medium-size iron \& steel enterprises in China. However, these systems did not yield desirable results for a variety of reasons. Therefore, it is significant to develop an expert system for sintering process conforming to the complicated raw material structure and imperfect basic automation system of iron \& steel enterprises in China.

Sintering process is a dynamic system with complex mechanism, multi-effect-factors, strong coupling and great lag. It is hard to develop precise mathematical models for control. Using artificial intelligence which simulates judgment and thinking of human being in process control is a powerful tool for control of this kind of complex systems. Therefore, the combination of mathematical model and artificial intelligence is a condign method for sintering process control.

Knowledge of sintering process control includes five types: production data, facts, mathematical models, heuristic knowledge and meta-knowledge. Diversity and complexity of sintering process control knowledge lead to the incompetence of single knowledge representation. Therefore, a hybrid knowledge representation model which is the combination of production rule, predicate logic and procedural representation is adopted. This hybrid system results in the multi base structure of knowledge base management, which is consisted of data base, fact base, model base and rule base. And the reasoning process of sintering process control expert system is multi-level-objective. A limited breadth first search strategy was put forward.

Since the early 1990s, funded by National Natural Science Foundation, National Research Project and some iron \& steel enterprises, chemical composition control of sinter, 
permeability control of sintering process, thermal control of sintering process, abnormity diagnosis of sintering process, etc. have been studied, based on the target and characteristics of sintering process control, and expert system for sintering process was developed and successfully applied in iron \& steel enterprises around China.

A neural network prediction model for chemical composition of sinter was developed using control method combined mathematical models with knowledge models. Rapid BP algorithm with adaptive variable step-size via linear reinforcement is adopted based on research of neural network models and their algorithms. Interval optimization is the control strategy adopted by this system. The control strategy of "Synchronized Optimization" can hardly be achieved because of the great dependency of each chemical composition and randomicity of their changes. Therefore, sinter chemical composition control should lay emphasis on keystone. Chemical composition control of sinter focuses on $\mathrm{R}$ and TFe control. Fluctuations of sintering process are mainly caused by fluctuations of permeability. Therefore, control of sintering process should center on permeability. Permeability-centered control strategy is as follow: when permeability is good, stable burning through point; when permeability is bad, improve permeability first, then consider keeping burning through point stable. Exhaust gas temperature in wind-boxes from head to tail of sintering machine is studied. Temperature Rising Position (TRP) is brought forward which is the position where temperature of exhaust gas in wind-boxes begins to rise. Stability of BTP can be realized by stability of TRP, which is achieved by adjustment of sintering machine speed, with predictive fuzzy control method, making use of the relation between sintering machine speed and TRP position.

\section{References}

CHEN Jinjiao. (1990). Computer Control Technology, Central South University of Technology Press, ISBN 7810203053, Changsha.

FANG Chongzhi, XIAO Deyun. (1988). Process Identification, Tsinghua University Press, ISBN 9787302002291, Beijing.

FU Juying, JIANG Tao, et al. (1996). Sintering and Pelletizing, Central South University of Technology Press, ISBN 7810208403, Changsha.

Fukagawa M, lyama Shunji, et al. (1991). Sinter Operation Control System with Artificial Intelligence. Kavasaki Steel Technical Report, Vol. 2, No. 3, (1991) 203-209, ISSN 03687236.

GUO Daiyi, LEI Wenyu, LIANG Shan. (1999). Fuzzy Control Technology and Its Applications in Metallurgy Industry, Chongqing University Press, ISBN 7562418926, Chongqing.

Kazuma N, et al. (1987). Sintering Process Control with "OGS". Sintering and Pelletizing, Vol. 12, No. 6 (1987) 41-48, ISSN 1000-8764.

MA Zhuwu. (2005). Automation for Ironmaking, Metallurgy Industry Press, ISBN 7-5024-36391 , Beijing.

Michnori Hattori, Hiroshi Fukuyo, et al. (1992). Development of Uniform and stable Sintering Technology in Keihin Sintering Plant. NKK Technical Report, No. 138 (1992) 8-15, ISSN 0468-2815.

Sasaki Fuka, et al. (1987). Development of Sintering Energy Consumption Control System (SECOS). Kavasaki Steel Technical Report, Vol. 19, No. 26, (1987) 21-25, ISSN 03687236 . 
Straka G. (1992). Process Control Model for Sinter Machine Speed. Metallurgical Plant and Technology International, Vol. 15, No. 5, (1992) 78-80, ISSN 0935-7254.

Takazo K, Mayumi Y, et al. (1987). Development and Application of an Integrated Simulation Model for Iron Ore Sintering. Ironmaking Proceedings, No. 46, (1987) 99106, ISSN 1528-5669

Unaki H, Miki K, et al. (1986). New Control System of Sinter Plants at Chiba Works, IFAC Automation in Mining, Mineral and Metal Processing, pp. 209-216, Tokyo, Japan, 1986. 


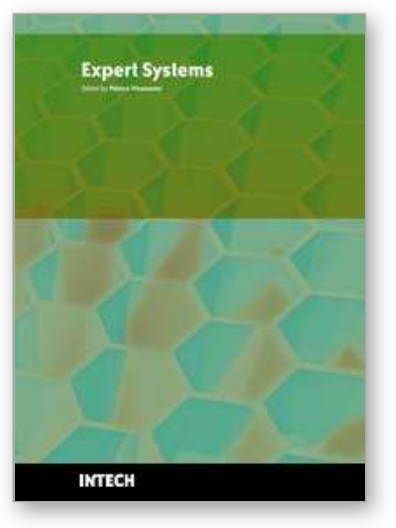

\author{
Expert Systems \\ Edited by Petrica Vizureanu
}

ISBN 978-953-307-032-2

Hard cover, 238 pages

Publisher InTech

Published online 01, January, 2010

Published in print edition January, 2010

Expert systems represent a branch of artificial intelligence aiming to take the experience of human specialists and transfer it to a computer system. The knowledge is stored in the computer, which by an execution system (inference engine) is reasoning and derives specific conclusions for the problem. The purpose of expert systems is to help and support user's reasoning but not by replacing human judgement. In fact, expert systems offer to the inexperienced user a solution when human experts are not available. This book has 18 chapters and explains that the expert systems are products of artificial intelligence, branch of computer science that seeks to develop intelligent programs. What is remarkable for expert systems is the applicability area and solving of different issues in many fields of architecture, archeology, commerce, trade, education, medicine to engineering systems, production of goods and control/diagnosis problems in many industrial branches.

\title{
How to reference
}

In order to correctly reference this scholarly work, feel free to copy and paste the following:

Xiaohui Fan, Xuling Chen and Yi Wang (2010). Expert System for Sintering Process Control, Expert Systems, Petrica Vizureanu (Ed.), ISBN: 978-953-307-032-2, InTech, Available from:

http://www.intechopen.com/books/expert-systems/expert-system-for-sintering-process-control

\section{INTECH}

open science | open minds

\author{
InTech Europe \\ University Campus STeP Ri \\ Slavka Krautzeka 83/A \\ 51000 Rijeka, Croatia \\ Phone: +385 (51) 770447 \\ Fax: +385 (51) 686166 \\ www.intechopen.com
}

\author{
InTech China \\ Unit 405, Office Block, Hotel Equatorial Shanghai \\ No.65, Yan An Road (West), Shanghai, 200040, China \\ 中国上海市延安西路65号上海国际贵都大饭店办公楼 405 单元 \\ Phone: +86-21-62489820 \\ Fax: +86-21-62489821
}


(C) 2010 The Author(s). Licensee IntechOpen. This chapter is distributed under the terms of the Creative Commons Attribution-NonCommercialShareAlike-3.0 License, which permits use, distribution and reproduction for non-commercial purposes, provided the original is properly cited and derivative works building on this content are distributed under the same license. 